\title{
Cyclic Voltammetry and RRDE Studies on the Electrochemical Behavior of Azetidinone Ester
}

\author{
M. Anbu Kulandainathan *, K. Kulangiappar, T. Raju, A. Muthukumaran \\ Electro Organic Division, Central Electrochemical Research Institute, Karaikudi-630 006, India
}

Received 28 May 2004; accepted 20 December 2004

\begin{abstract}
Azetidinone ester is the key intermediate during the synthesis of injectable cephalosporin compounds. This intermediate is undergoing electrochemical reaction during the process of conversion from penicillin to cephalosporin. The CV and RRDE studies clearly indicate that electro-reduction of this compound is taking place in three steps under the condition. The first two peaks correspond to the two, one electron transfers and the third one is due to the proton addition from the non-aqueous solvent. And during the process, the cyclisation is also taking place in order to neutralise the charge. Further CV and RRDE studies with the addition of small amount of water to the above system clearly confirm the mechanism. This was very well confirmed by the FTIR analysis of the product obtained from the bulk electrolysis.
\end{abstract}

Keywords: azetidinone ester, electro reduction, cyclic voltammetry, RRDE, electrode kinetics.

\section{Introduction}

Strains due to organisms, which are resistant to penicillin, can be attacked by the major class of drugs comprising of cephalosporin antibiotics. The large volumes of oral cephalosporin are produced by expanding the five-membered ring of the fermented penicillin $\mathrm{G}$ or $\mathrm{V}$, to create the six membered ring of a cephalosporin. However, the use of penicillin to manufacture cephalosporin antibiotics, such as ceftibuten or cefaclor, requires as many as 14 chemical transformations in addition to the ring expansion step, in which 7-ACA is an important intermediate. This makes the production of cephalosporin antibiotics long and costly [1]. A very cheap 5 steps organic synthetic process has been developed to synthesize cephalosporin by making use of Pen-G, which is a low cost material and in which azetidinone ester is a key intermediate, is substituting substantially 7-ACA in the cephalosporin market [2-3].

\footnotetext{
*Corresponding author. E-mail address: manbu123@yahoo.com
} 


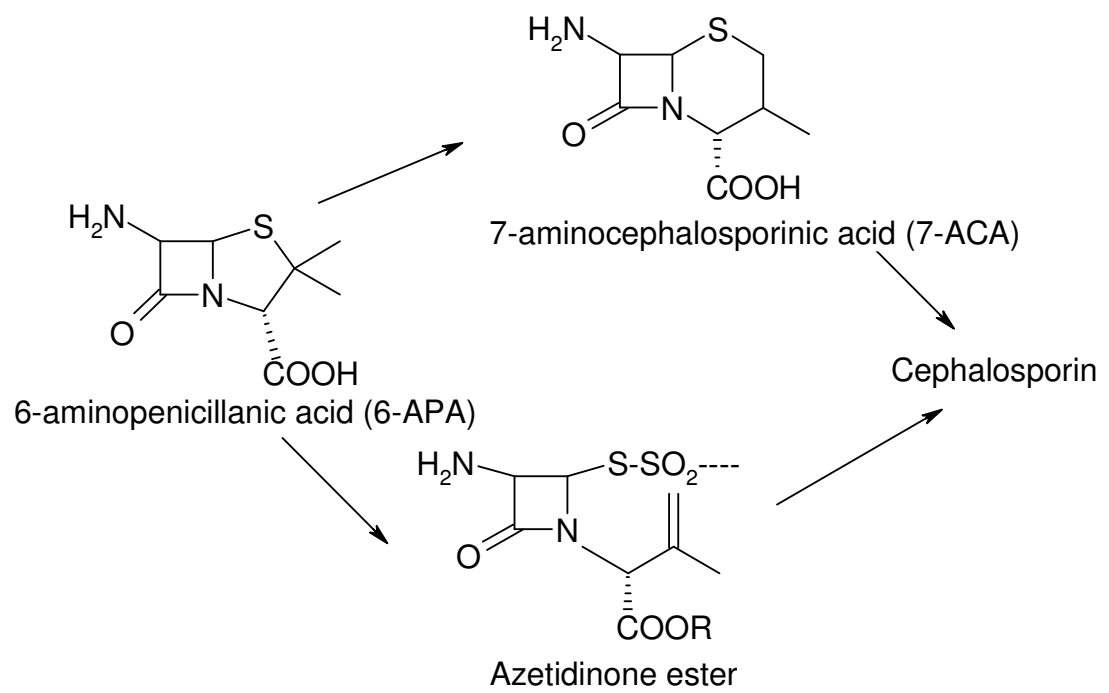

The conversion of azetidinone ester to cephalosporin comprises the electrochemical ene-type chlorination and the ring closure with base [4-5].

Bersier et al. [6] in their review clearly brings out the electrochemical behavior of azetidin-2-one, 4-acetoxy-azetidin-2-one, 3(R)-hydroxyethyl-4-acetoxyazetidin-2-one intermediates in the synthesis of Penems (IV) and Carbapenem (V) non-classical $\beta$-lactam antibiotics. Jones et al. were first to describe the polarographic reduction of cephalosporin C, cephalothin and cephaloridine [7]. More fundamental investigation, aimed at elucidating the mechanism of electrochemical reductions of cephalosporanic acids, was then conducted by Ochiai et al. [8-9]. These investigations showed that cephalosporin $\mathrm{C}$ and related compounds are reduced by a two-electron process to 3-exomethoxylenecephams [10]. Unlike Baldwin et al. [11], who studied similar process at low $\mathrm{pH}$, Ochiai et al. ran their reactions at high $\mathrm{pH}$ obtaining promising yields. But there is no literature available on the electrochemical reduction of the particular intermediate (substituted acetidinone ester).

In order to gain a better understating of the electrochemical behaviour of azetidinone ester and to extend the applicabilities of azetidinone ester, detailed kinetic data involving the electrochemical behavior of the intermediate (azetidinone ester) are very important. So, the present study is to investigate the mechanism of reduction of the substituted azetidinone ester using cyclic voltammtery, rotating ring-disc electrode and bulk electrolysis techniques.

\section{Experimental section}

\section{Chemicals}

Azetidinone ester (recrystallised from acetonitrile and isopropyl alcohol, $+99.5 \%$ purity by HPLC) was from SPIC Pharma, Chennai. Tetra-n-butylammonium perchlorate was from Merck and was used without further purification. Dimethylformamide was distilled under reduced pressure and stored in $4 \mathrm{~A}^{\circ}$ molecular sieves and it was tested for water content before starting each 
experiment. Dry nitrogen gas was purged for $30 \mathrm{~min}$ prior to electrochemical experiments.

The chemical structure of the azetidinone ester is

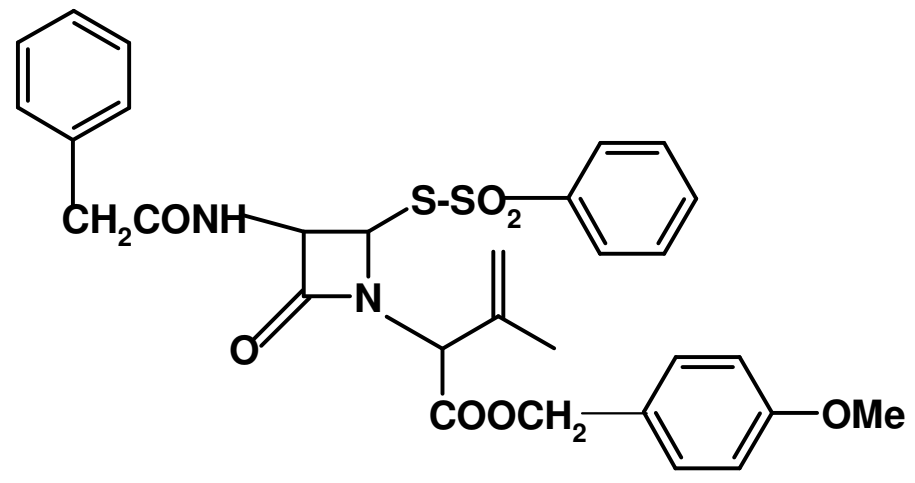

Chemical name is: 3-methyl-2-(4'-phenyl sulphonyl thio,-3'-phenyl acetamido, 2'- azetidinone-1'-yl)-3-butenoic acid, p-methoxy benzyl ester (melting point = $117-119{ }^{\circ} \mathrm{C}$, molecular weight $=595$, diameter $=1.41 \mathrm{~A}^{\circ}$ ).

\section{Instrumentation}

The CV and RRDE experiments were performed by using a AFRDE5 bipotentiostat supplied by PINE Instruments, USA, and the working electrode rotation was controlled by a Pine Instruments MSRX speed controller. For all electrochemical studies, a three-electrode configuration was followed. The working electrode was glassy carbon (area $0.3 \mathrm{~cm}^{2}$ ) in the case of cyclic voltammetry. A large area platinum foil and a $\mathrm{Ag} / \mathrm{AgCl}$ electrode were used as counter and reference electrodes, respectively. The working electrode for the RRDE study was glassy carbon disc and glassy carbon ring electrodes. The dimensions for the ring and disc electrode were as follows: disc radius is $3 \mathrm{~mm}$, inner radius of the ring $3.75 \mathrm{~mm}$, ring outer radius $4.25 \mathrm{~mm}$ and whole assembly radius $7.50 \mathrm{~mm}$. The areas of the disc and ring electrodes were $0.28 \mathrm{~cm}^{2}$ and $0.13 \mathrm{~cm}^{2}$, respectively. All potentials refer to $\mathrm{Ag} / \mathrm{AgCl}$ reference electrode.

\section{Preparative electrolysis}

Preparative scale electrolyses were carried out in $1 \mathrm{~g}$ batch experiment under potentiostatic controlled electrolyisis technique under nitrogen atmosphere at $2.6 \mathrm{~V}$ vs. $\mathrm{Ag} / \mathrm{AgCl}$ for $10 \mathrm{hrs}$. A three-electrode configuration was followed with the glassy carbon (area $9.0 \mathrm{~cm}^{2}$ ) as a working electrode, a large area platinum foil and a $\mathrm{Ag} / \mathrm{AgCl}$ electrode were used as a counter and reference electrode, respectively. After completion of electrolysis, the product was washed with ether, and water was added to the solution to remove the supporting electrolyte. After slow removal of the supporting electrolyte the solution was distilled under reduced pressure to remove the solvent. Then the product was separated from the reactant by column chromatography. The HPLC analysis was followed using Shimadzu, Japan make-VP series-10AT model, in order to check the product formation. The yield of the product was about $68 \%$ by HPLC. The product was also analysed through FTIR spectrometer (Perkin-Elmer Paragon 500, UK). The 
supporting electrolyte used for all the electrochemical studies was $0.5 \mathrm{M}$ terta-nbutylammonium perchlorate in dimethylformamide solution. The concentration of the azetidinone ester was $4 \mathrm{mM}$, except in the case of concentration study where the concentration will be mentioned.

\section{Results and discussion}

Electrochemical reduction of the azetidinone ester was followed by both cyclic voltammetry $(\mathrm{CV})$ and rotating ring disc electrode (RRDE) techniques. In these studies, a qualitative result on the number of electrons taking part in the electrochemical step can be obtained from $\mathrm{CV}$ and the quantitative results on electrochemical kinetics can be obtained from RRDE technique. These results were further confirmed by bulk electrolysis, and also product confirmation using other analytical techniques.

\section{Cyclic voltammetry}

Fig. 1 shows the $\mathrm{CV}$ obtained for the different concentration of azetidinone ester from $0.6 \mathrm{~V}$ to $-2.5 \mathrm{~V}$ vs. $\mathrm{Ag} / \mathrm{AgCl}$ reference electrode. It clearly shows that there are three different cathodic peaks at a) -1.08 , b) -1.8 , and c) $-2.35 \mathrm{~V}$ vs. $\mathrm{Ag} / \mathrm{AgCl}$. Accordingly, the first two peaks correspond to two-electron transfer in two steps followed by proton addition from solvent as third peak. And the anodic peak obtained at $0.4 \mathrm{~V}$ vs. $\mathrm{Ag} / \mathrm{AgCl}$ may be due to desorption of the substance from the electrode surface. It can be seen from the inset of Fig. 1 that for the first peak the charge increases logarithmically with square root of concentration, but for the other two peaks the charge increases proportionally to the square root of the concentration.

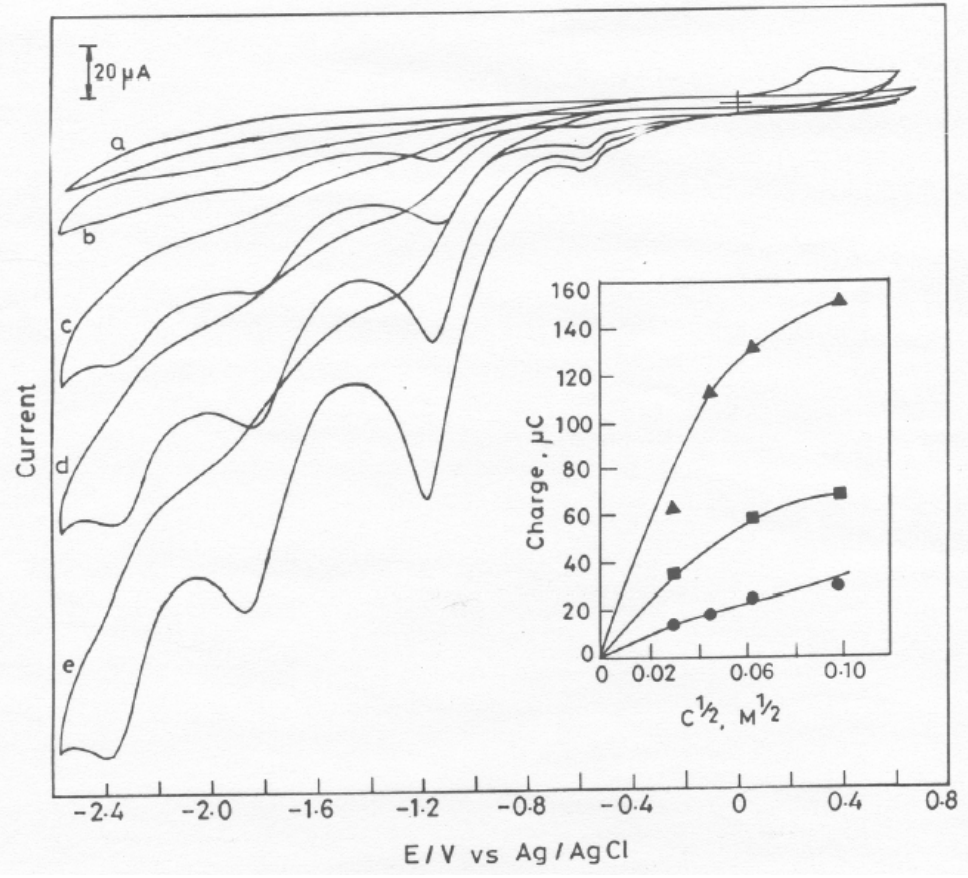

Figure 1. Effect of concentration on the $\mathrm{CV}$ recorded for the reduction of different concentration of azetidinone ester on GC electrode in DMF containing 0.5 M (TBA) $\mathrm{ClO}_{4}$. Sweep rate: $25 \mathrm{mV} \mathrm{s}^{-1}$ a) 2, b) 4, c) 8, d) 10, and e) $15 \mathrm{mM}$. 
Fig. 2 shows that as the sweep rate increases the current also increases and peak potentials shift to more negative values. And from the inset of the figure it can be seen that the reduction peak current is proportional to the square root of the potential scan rate, as expected for the peak whose current is controlled by diffusion. Collectively it can be seen from the $\mathrm{CV}$ data that the electro-reduction of this organic compound is taking place in two steps followed by proton addition.

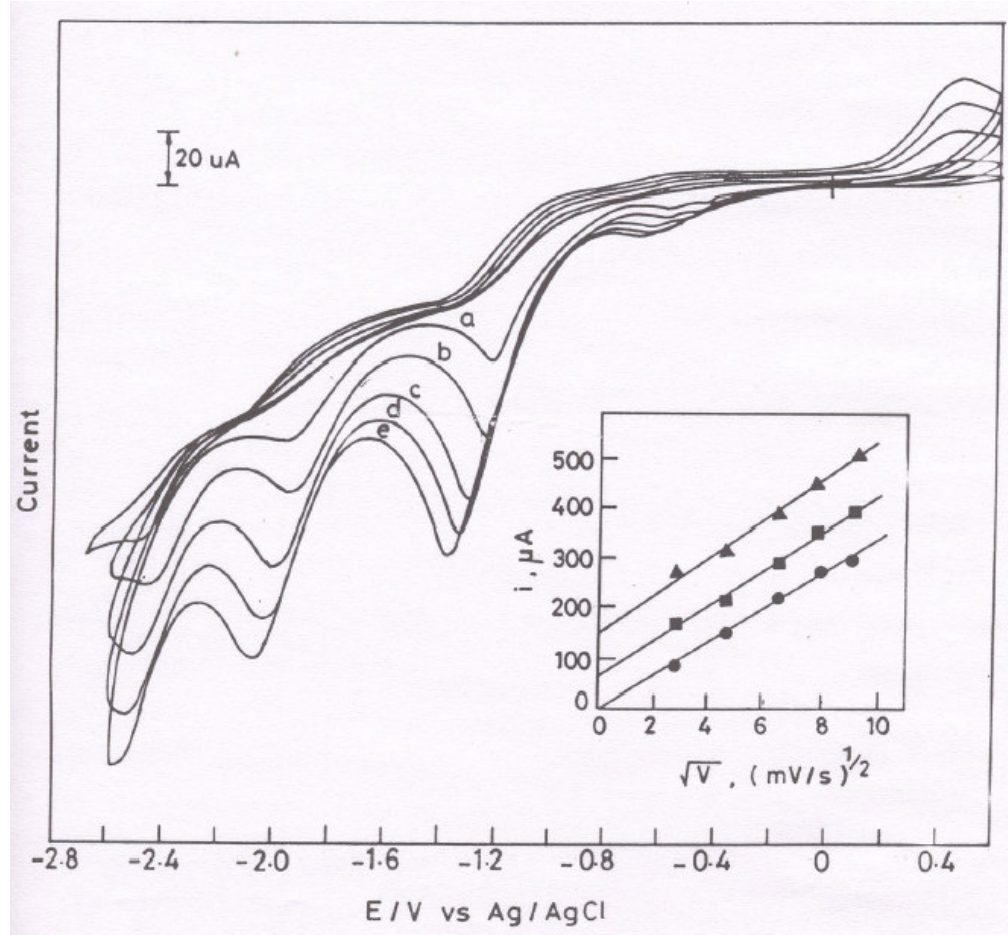

Figure 2. Effect of sweep rate on the $\mathrm{CV}$ recorded for the reduction of $4 \mathrm{mM}$ azetidinone ester on GC electrode in DMF containing $0.5 \mathrm{M}$ (TBA) $\mathrm{ClO}_{4}$. a) 10 , b) 25 , c) 50 , d) 75 , and e) $100 \mathrm{mV} \cdot \mathrm{s}^{-1}$.

\section{Rotating ring disc electrode voltammetry}

Fig. 3 B shows three well-developed cathodic steps corresponding to the first two one-electron transfers and the third due to proton addition from the solvent for the reduction of azetidinone ester in $0.5 \mathrm{M}$ (TBA) $\mathrm{ClO}_{4}$ in DMF, for different rotation rates. Limiting current $\left(\mathrm{i}_{\mathrm{L}}\right)$ of these steps is controlled by convectional diffusion, as verified by the Levich analysis [12]. It can be easily seen from the inset in Fig.3. The second order rate constant, k, can be calculated from the limiting currents by using the rate equation [13]. For the three different peaks, it corresponds to $2.0,3.3$ and $5.1 \mathrm{M}^{-1} \mathrm{~s}^{-1}$, respectively. The cathodic reduction voltammogram of the ring is shown in Fig. 4. This voltammogram for different rotation of the ring was recorded when the potential of the disc was fixed at -1.2 $\mathrm{V}$ vs. $\mathrm{Ag} / \mathrm{AgCl}$, i.e., this potential corresponds to the first peak of the disc voltammogram. It is very clear from the figure that the three steps in the disc 
have become two. So, it is clear that the first potential is due to the one electron transfer. From the inset of Fig. 4, it is seen that at different rotation, this also behaves like convectional diffusion.

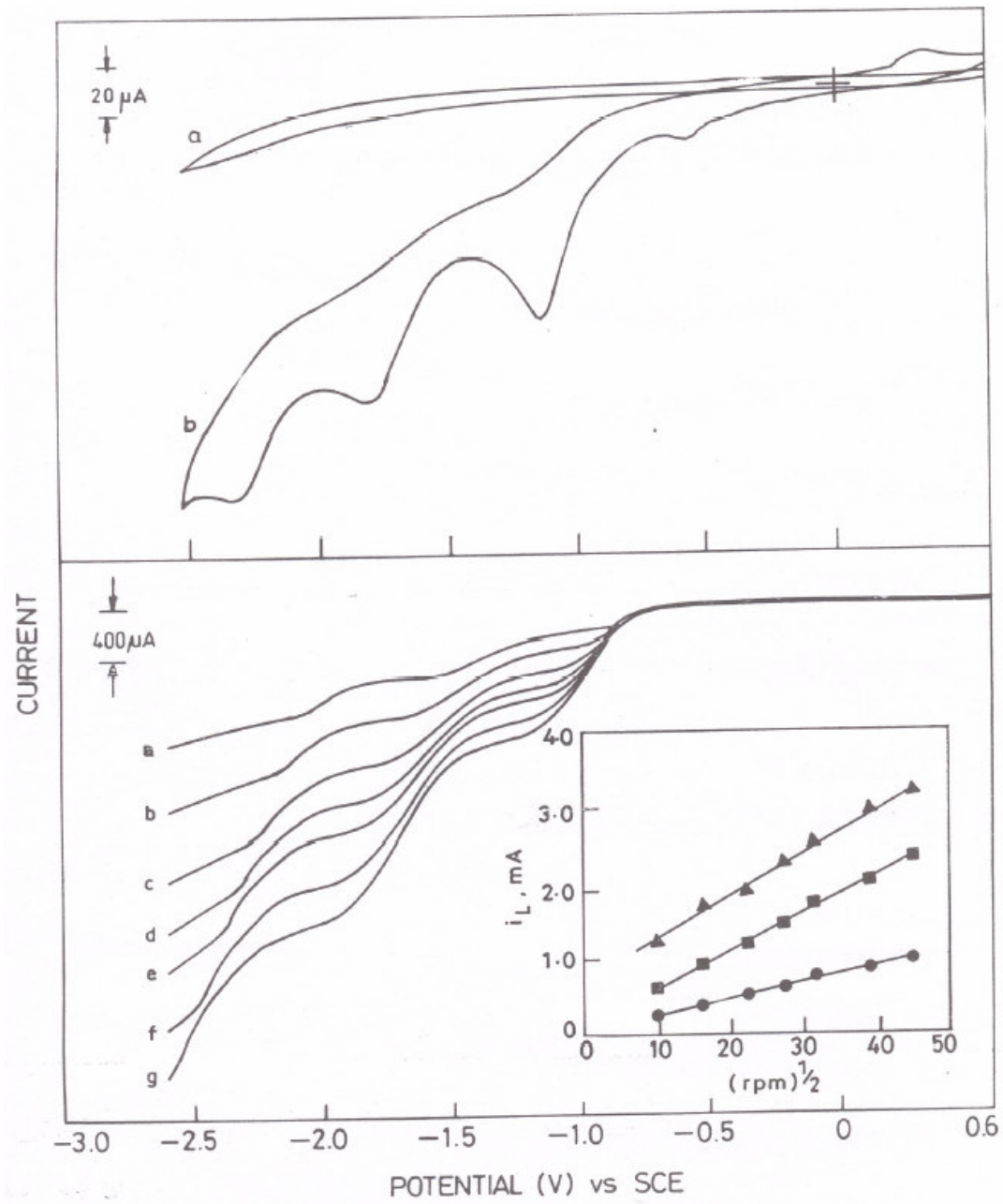

Figure 3. A) $\mathrm{CV}$ for $4 \mathrm{mM}$ azetidinone ester in $0.5 \mathrm{M}$ (TBA) $\mathrm{ClO}_{4}$ in $\mathrm{DMF}$ solution at $\mathrm{GC}$ rotating disc electrode. Sweep rate $25 \mathrm{mV} \mathrm{s}^{-1}$. a) Background current.

B) Cathodic scan at different rotation speed of GC disc electrode.

a) 100, b) 250 , c) 500, d) 750, e) 1000, f) 1500 , and g) $2000 \mathrm{rpm}$.

\section{Effect of water on the system}

In order to justify the above proposed mechanism, CV and RRDE experiments were carried out for the above system with the addition of $0.05 \mathrm{M}$ water (i.e., 4 $\mathrm{mM}$ azetidinone ester and $0.05 \mathrm{M} \mathrm{H}_{2} \mathrm{O}$ in $0.5 \mathrm{M}(\mathrm{TBA}) \mathrm{ClO}_{4}$ in $\left.\mathrm{DMF}\right)$. There are three protonating systems available, $\mathrm{H}^{+}, \mathrm{HA}$ and $\mathrm{H}_{2} \mathrm{O}$, for the study, and $\mathrm{H}_{2} \mathrm{O}$ was taken as the protonating system to study the last step of the mechanism. Water is a Bronsted acid with a $\mathrm{pK}_{\mathrm{a}}$ value of 15.74. Fig. 5A shows the cyclic voltammogram of the system indicating the last step as the wave, which clearly shows that the last step is the fast one. And Fig. 5B shows the rotating disc voltammogram at different rotation speed indicating the two step process, and 
from the inset of the figure, it is clear that $i_{L}$ vs. $(r p m)^{1 / 2}$ the line is passing through origin, which confirms that the two single electron addition is followed by second order kinetics like without water. The voltammogram of the ring at stationary and at different rotation (Fig. 6A and B), when the disc potential was fixed at $-1.2 \mathrm{~V}$ vs. $\mathrm{Ag} / \mathrm{AgCl}$, shows the intermediate formed at the disc immediately undergoing some kind of reaction very fast.

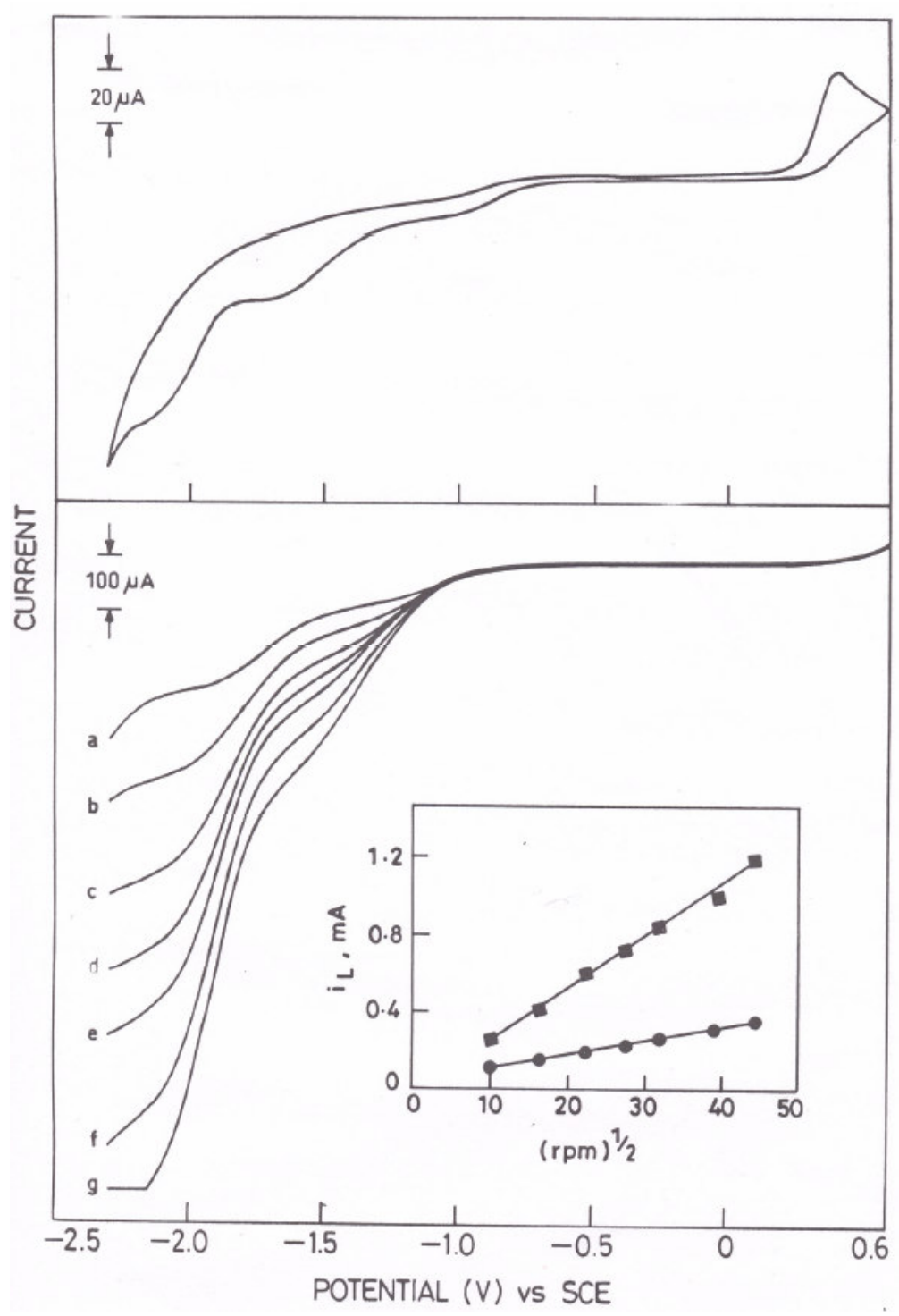

Figure 4. A) $\mathrm{CV}$ for $4 \mathrm{mM}$ azetidinone ester in $0.5 \mathrm{M}$ (TBA) $\mathrm{ClO}_{4}$ in $\mathrm{DMF}$ solution at $\mathrm{GC}$ rotating ring electrode. Sweep rate $25 \mathrm{mV} \mathrm{s}^{-1}$. Disc electrode potential: $-1.2 \mathrm{~V}$ vs. $\mathrm{Ag} / \mathrm{AgCl}$. B) Cathodic scan at different rotation speed of GC ring electrode. a) 100, b) 250 , c) 500 , d) 750 , e) 1000 , f) 1500 , and g) $2000 \mathrm{rpm}$. 


\section{Preparative electrolysis}

Fig. $7 \mathrm{a}$ and $7 \mathrm{~b}$ show the FTIR spectra of the reactant and product, respectively. It is clear from the figure that the peaks obtained in the product between 1800 and $1500 \mathrm{~cm}^{-1}$ are completely absent, which are present in the reactant. So it is clear that some groups are removed from the reactant. The removed peaks are $\mathrm{S}=\mathrm{O}$ $1370 \mathrm{~cm}^{-1}$, -S-S- $1760 \mathrm{~cm}^{-1}$, S-H $2565 \mathrm{~cm}^{-1}$, and the peak at 3460 and $3400 \mathrm{~cm}^{-1}$ is due to the ketonic group at the four member ring, which is present in both product and reactant. So it is clear that the $-\mathrm{SO}_{2}-\mathrm{Ph}$ group is removed from the reactant and the ketonic group is unaffected during the reduction process.

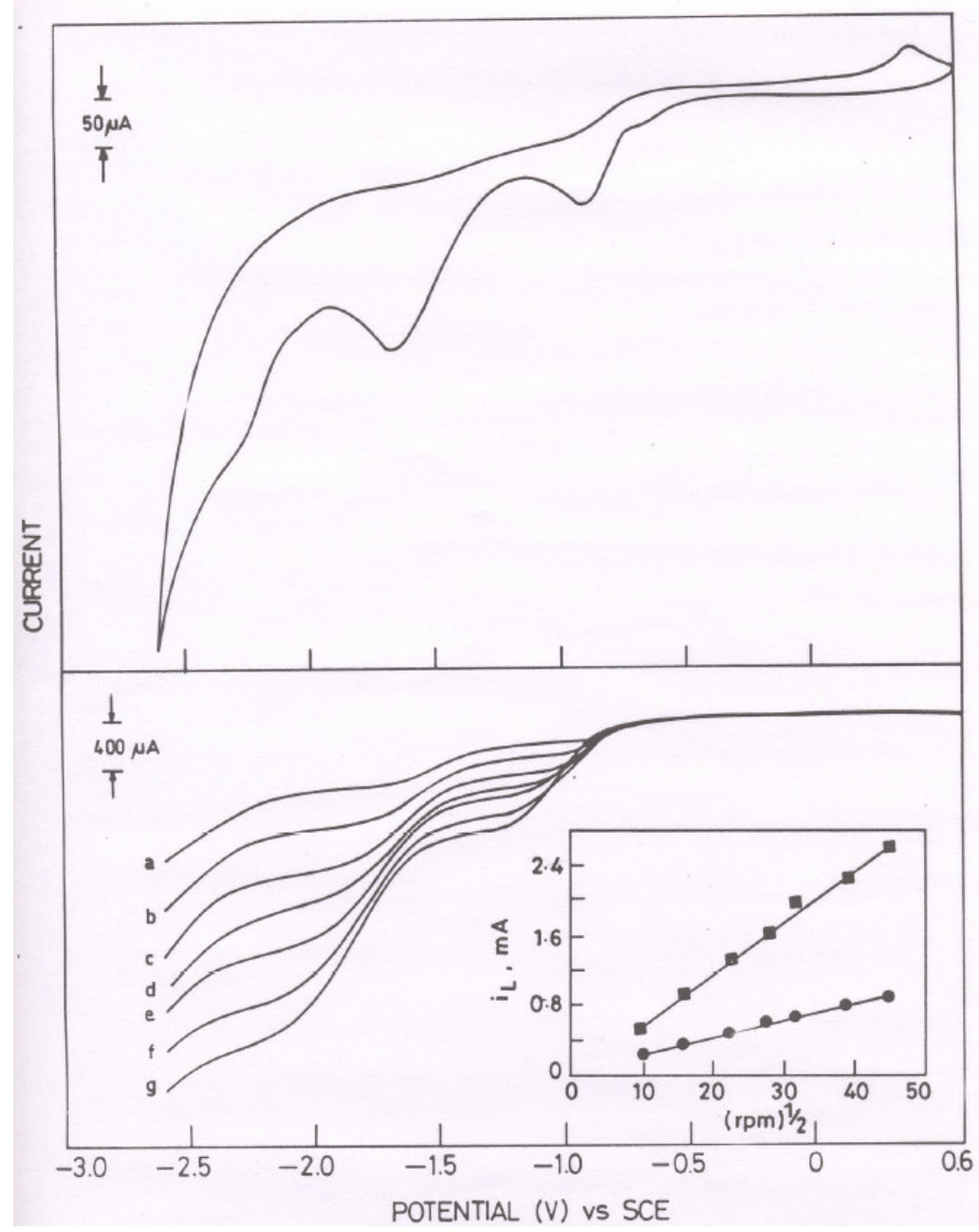

Figure 5. A) $\mathrm{CV}$ for $4 \mathrm{mM}$ azetidinone ester in $0.5 \mathrm{M}$ (TBA) $\mathrm{ClO}_{4}$ and $0.05 \mathrm{M} \mathrm{H}_{2} \mathrm{O}$ in DMF solution at GC rotating disc electrode. Sweep rate $25 \mathrm{mV} \mathrm{s}^{-1}$. B) Cathodic scan at different rotation speed of GC disc electrode. a) 100, b) 250, c) 500, d) 750 , e) 1000, f) 1500, and g) $2000 \mathrm{rpm}$. 


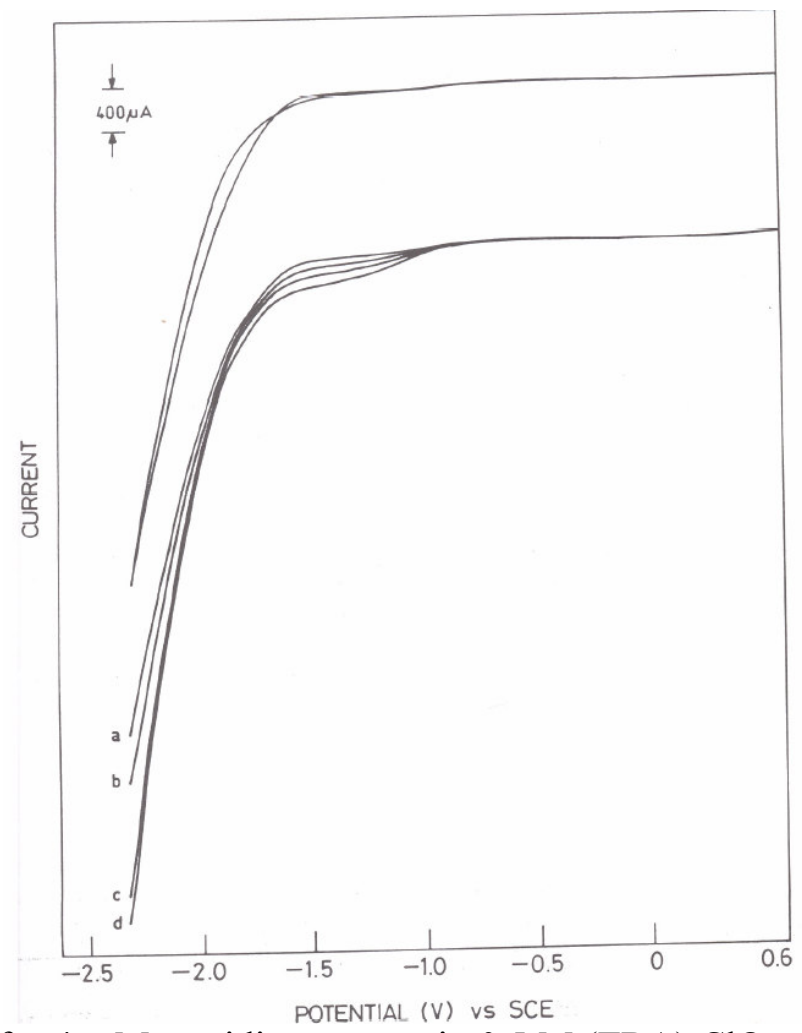

Figure 6. A) $\mathrm{CV}$ for $4 \mathrm{mM}$ azetidinone ester in $0.5 \mathrm{M}$ (TBA) $\mathrm{ClO}_{4}$ and $0.05 \mathrm{M} \mathrm{H}_{2} \mathrm{O}$ in DMF solution at GC rotating ring electrode. Sweep rate $25 \mathrm{mV} \mathrm{s}^{-1}$. Disc electrode potential: $-1.2 \mathrm{~V}$ vs. $\mathrm{Ag} / \mathrm{AgCl}$. B) Cathodic scan at different rotation speed of $\mathrm{GC}$ ring electrode. a) 100 , b) 250 , c) 500, d) 750, e) 1000, f) 1500, and g) $2000 \mathrm{rpm}$.

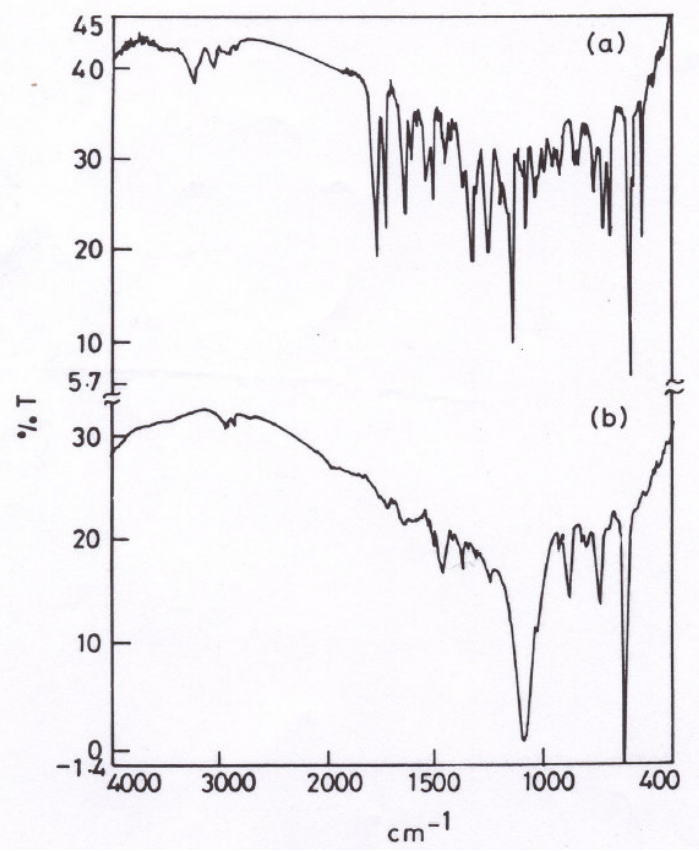

Figure 7. FTIR spectrum of a) azetidinone ester and b) reduced product. 


\section{Mechanistic aspects}

The proposed reaction of azetidinone ester is believed to be similar to that of the intramolecular reductive coupling of benzene -1,2-diacrylate ester analogues proposed by Baizer [14] and for the transformation of penicillin by Torii [15], which proceed with two electrons reduction followed by the hydrogen abstraction from the solvent [16]. The observation from CV and RRDE studies of both non-aqueous and addition of small amount of Bronsted acid clearly confirms this mechanism.
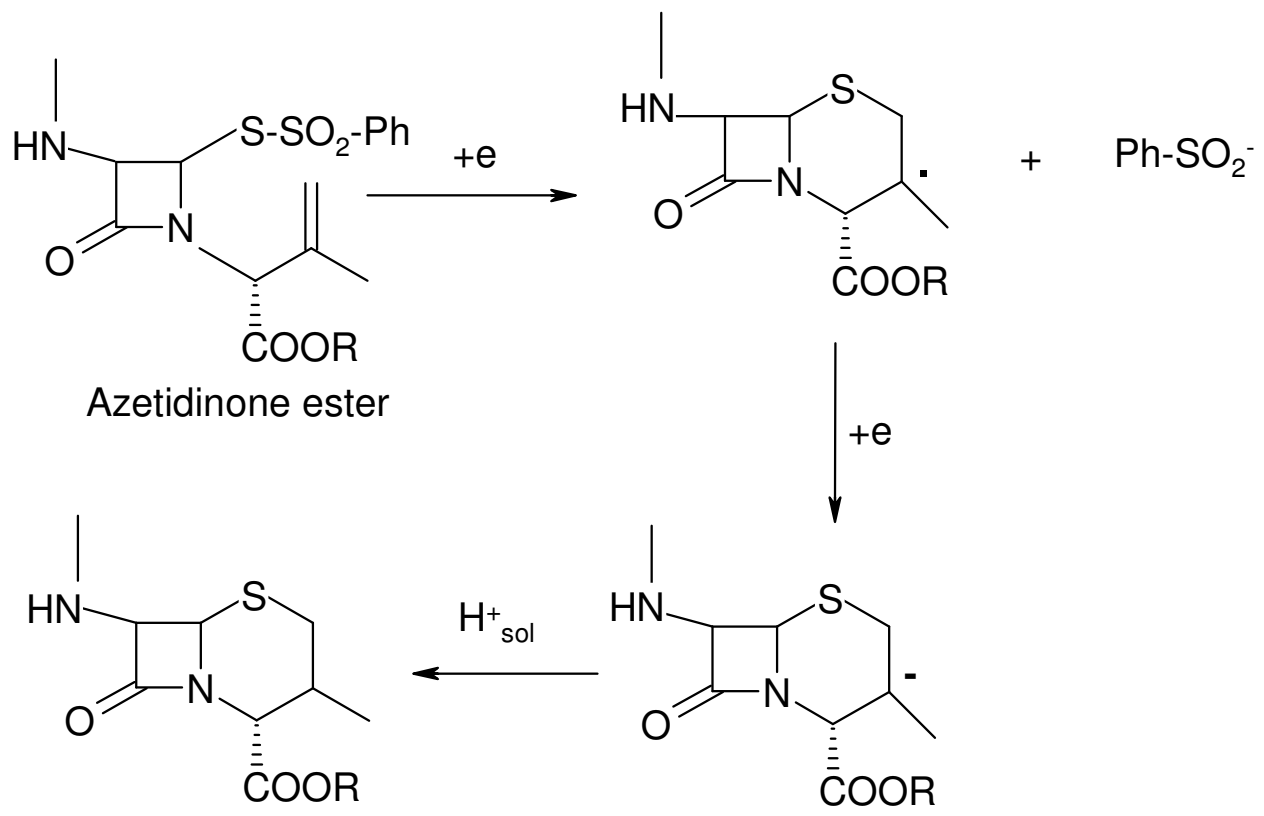

\section{Conclusions}

Azetidinone ester is the key intermediate during the synthesis of injectable cephalosporin compounds. This intermediate is undergoing electrochemical reaction during the process to get final product. The CV and RRDE studies clearly indicate that electro-reduction of this compound, is taking place in three steps under the condition. And during the process, the cyclisation is also taking place in order to neutralise the charge. This was very well confirmed by the FTIR analysis of the product obtained from the preparative scale electrolysis.

\section{Acknowledgements}

The authors thank The Director, Central Electrochemical Research Institute, Karaikudi, India, for kindly permitting us to publish these results.

\section{References}

1. P. Zelenay, V. Menon, H. Zhang, C.R. Martin, D. Walker, J. Lee, E. Bernasconi, L. Sogli, Electrochemical Soc., Proceedings 97-7 (1997) 45.

2. "Recent advances in the chemistry of $\beta$-lactam antibiotics", Ed. By J. Elks, Chem. Soc. Burlington House, London (1977), p.101. 
3. S. Karady, L.N. Weinstock, F.E. Roberts, J. Ten Broeke, R.F. Shuman, A.M. Hoinowski, S.H. Pines, M. Sletzinger, Tetrahedron Lett. 17 (1976) 2404.

4. S. Torii, H. Tanaka, N. Tada, S. Nagao, M. Sasaoka, Chem. Lett. (1984) 877.

5. $\quad$ S. Torii, H. Tanaka, T. Siroi, Tetrahedron Lett. 23 (1982) 2187.

6. P.M. Bersier, L. Carlsson, J. Bersier, $10^{\text {th }}$ International Forum on Applied Electrochemistry, Sand Key, Florida, November 1996.

7. I.F. Jones, J.E. Page, C.T. Rhodes, J. Pharmac. 20 (1968) 45S.

8. M. Ochiai, O. Aki, A. Morimoto, T. Okada, K. Shinozaki, Y. Ashi, Tetrahedron Lett. 23 (1972) 2341.

9. M. Ochiai, O. Aki, A. Morimoto, T. Okada, T. Kaneko, Y. Ashi, Tetrahedron Lett. 23 (1972) 2345.

10. D.A. Hall, J. Pharm. Sci. 62 (1973) 980.

11. J.E. Baldwin, R.M. Adlington, N.P. Cronch, I.A.C. Pereira, Tetrahedron 9 (1993) 4907.

12. V.G. Levich, "Physicochemical Hydrodynamics", Prentice Hall: Englewood Cliffs, NJ, 1962.

13. A.J. Bard, L.R. Faulkner, "Electrochemical Methods: Fundamentals and Applications", John Wiley, N.Y., 1980, Chapter 11.

14. J.P. Petrovich, J.D. Anderson, M.M. Baizer, J. Org. Chem. 31 (1966) 3897.

15. S. Torii, $7^{\text {th }}$ Int. Forum, Electrolysis in the Chemical Industry, Buena Vista, Nov. 7-11, 1993.

16. F. D’Souza, J. Choi, W. Kutner, J. Phys. Chem. B 102 (1998) 4247. 